\title{
Developing the Science of Health Care Emergency Preparedness and Response
}

\author{
Gabor D. Kelen, MD, FACEP, and Melissa L. McCarthy, ScD, Guest Editors
}

M any of the disasters and large-scale emergencies of the past decade in the United States have required a major organized medical response by communities, regions, and state and federal agencies. Developing a "disaster medical capability that can immediately re-orient and coordinate existing resources within all sectors to satisfy the needs of the population during a catastrophic health event" is an important priority for our nation. ${ }^{1}$ Since the terrorist attacks of September 11, 2001, the federal government has invested substantial resources and effort into improving our country's medical emergency preparedness and response capabilities. ${ }^{1-4}$ Given that the initial response to a catastrophic health event relies on local resources, the true test of our domestic preparedness and response capabilities requires evaluation at the local level, in thousands of jurisdictions across the country. Health care facilities, particularly hospitals, often play a key role in communities' medical emergency preparedness and response efforts. This special issue of Disaster Medicine and Public Health Preparedness examines the science behind hospital emergency preparedness and response.

In this issue, Sauer et al highlight some of the actions taken by the federal government and others to improve hospital preparedness and response capabilities. ${ }^{5}$ For example, the federal government has developed a number of strategic documents (eg, National Incident Management System) and passed a number of laws (eg, the Public Health Security and Bioterrorism Preparedness and Response Act) to promote the adoption of a consistent incident command management system and an all-hazards approach to emergency preparedness and response across hospitals and other first-responder entities. The Joint Commission, the American Society for Testing and Materials, the National Fire Protection Association, and others have introduced rigorous standards to improve the emergency management capabilities of hospitals. How influential these different factors have been on improving hospitals' emergency preparedness capabilities is uncertain due to the lack of formal research in this area. ${ }^{6}$

Based on actual catastrophic health events occurring during the past decade, it is clear that hospitals' emergency preparedness and response capabilities vary greatly in the United States. As summarized by Barbera and colleagues, there are many reasons for this unevenness, including a tight fiscal environment, per- ception of minimal risk, and concern over business and legal risks associated with emergency preparedness and response activities. ${ }^{6}$ In addition, as raised by McCarthy et al, there is no well-accepted, validated framework of emergency management capabilities that hospitals can use to guide and prioritize their emergency preparedness and response activities. ${ }^{7}$

Macintyre and colleagues point out in their article on health care emergency management that there is no clearly defined discipline that is responsible for medical emergency preparedness and response. ${ }^{8}$ Instead, within the health care industry, many independent and competing initiatives by medical practitioners, health care administrators, engineers, safety and security personnel, and so forth have emerged to address disaster preparedness and response. Each of these efforts has its own approach, terminology, and conceptual foundation, which make it difficult to integrate efforts and to reach consensus on the "knowledge and skill sets that healthcare systems must have to become adequately ready for emergencies and disasters." care emergency management as the discipline to unify the various health care-related emergency response initiatives.

Similarly, development of a scientific approach to study health system preparedness has been significantly hindered by a fundamental lack of interest by agencies, both government and private, that otherwise support traditional basic, clinical, and operational research. Although biodefense has received considerable funding, ${ }^{9}$ the National Institutes of Health, the Centers for Disease Control and Prevention, and the National Science Foundation have no organized programs within their institutes and departments that promote the science or development for health care preparedness. The Department of Homeland Security has a single Center of Excellence among 14 that has some concentration of research interest in health and the public health sector. The Agency for Healthcare Research and Quality has been the most earnest and successful in promoting health system/public health research related to preparedness, but it is woefully underfunded.

If the United States is serious about the strategic importance of health care and public health preparedness, then the federal government must instruct its lead research agencies to develop specific funding programs to promote and develop the science in this area of urgent need. Without the establishment of a com- 
prehensive discipline of disaster medicine and public health preparedness, not only will our operational preparedness and response capabilities remain inconsistent but the science that drives our efforts will continue to lack focus and rigor. We need a dedicated discipline of knowledgeable and well-trained scientists to test different policies and practices and determine how best to ready our country for future catastrophic health events. The majority of articles in this special issue are meant to stimulate and support the development of this fledging discipline in the hope that it will mature into an established scientific field.

\section{About the Authors}

The authors are with the Department of Emergency Medicine, Johns Hopkins University School of Medicine.

\section{Authors' Disclosures}

The authors report no conflicts of interest.

ISSN: 1935-7893 @ 2009 by the American Medical Association and Lippincott Williams \& Wilkins.

DOI: 10.1097/DMP.0b013e3181a3e290

\section{REFERENCES}

1. The White House. Homeland Security Presidential Directive/HSPD-21. http://www.whitehouse.gov/news/releases/2007/10/20071018-10.html. Accessed October 27, 2008.
2. HHS Bioterrorism Council. HHS plan to combat bioterrorism and other public health emergencies. http://www.hhs.gov/aspr/opeo/documents/ hhsplncombat.html. 2009. Accessed February 6, 2009.

3. Agency for Healthcare Research and Quality. Public health emergency preparedness. http://www.ahrq.gov/prep/index.html. Accessed February 6, 2009.

4. Centers for Disease Control and Prevention. Coordinating Council for Terrorism Preparedness and Emergency Response. Public Health Preparedness: Mobilizing State by State. A CDC Report on the Public Health Emergency Preparedness Cooperative Agreement Program. http://emergency.cdc. gov/publications/feb08phprep/pdf/feb08phprep.pdf. Accessed February 6, 2009.

5. Sauer LM, McCarthy ML, Knebel A, Brewster P. Major influences on hospital emergency management and disaster preparedness. Disaster Med Public Health Preparedness. 2009;3(Suppl 1):S68-S73.

6. Barbera JA, Yeatts DJ, MacIntyre AG. The challenge of hospital emergency preparedness. Disaster Med Public Health Preparedness. 2009;3 (Suppl 1):S74-S82.

7. McCarthy ML, Brewster P, Hsu EB, MacIntyre AG, Kelen GD. Consensus and tools needed to measure health care emergency management capabilities. Disaster Med Public Health Preparedness. 2009;3(Suppl 1): S45-S51.

8. MacIntyre AG, Barbera JA, Brewster P. Health care emergency management: establishing the science of managing mass casualty and mass effect incidents. Disaster Med Public Health Preparedness. 2009;3(Suppl 1):S52S58.

9. Franco C. Billions for biodefense: federal agency biodefense funding: FY2008-2009. Biosecur Bioterror. 2008;6:131-146. 